\title{
The Effects of Age and Liver Disease on the Disposition and Elimination of Diazepam in Adult Man
}

\author{
U. Klotz, G. R. Avant, A. Hoyumpa, S. Schenker, and G. R. Winkinson \\ From the Departments of Pharmacology and Medicine, Vanderbilt University \\ School of Medicine, and Veterans Administration Hospital, \\ Nashville, Tennessee 37232
}

A B S T R A C T This study investigates the separate effects of age and hepatocellular liver disease on the disposition and elimination of diazepam (Valium) in man. The drug was given either by rapid intravenous injection $(0.1 \mathrm{mg} / \mathrm{kg})$ or orally $(10 \mathrm{mg})$ to 33 normal volunteers ranging in age from 15 to $82 \mathrm{yr}$ as well as to 9 individuals with alcoholic cirrhosis, 8 with acute viral hepatitis, and 4 with chronic active hepatitis.

In the normal individuals, the terminal plasma halflife of diazepam, $(t / \beta))$ exhibited a striking agedependence; at $20 \mathrm{yr}$ the $\mathrm{t}$ ( $\beta$ ) was about $20 \mathrm{~h}$, but it increased linearly with age to about $90 \mathrm{~h}$ at $80 \mathrm{yr}$. The plasma clearance of diazepam in the majority of the normal subjects was between 20 and $32 \mathrm{ml} / \mathrm{min}$ and showed no significant age-dependence. Cigarette smoking did not affect the half-life or the clearance. Additionally, neither the plasma binding $(97.4 \pm 1.2 \%$, mean $\pm \mathrm{SD})$ nor the blood/plasma concentration ratio (0.58 $\pm 0.16)$ of diazepam showed any age-related changes $(P>0.05)$. By contrast, analysis of the intravenous data according to a two-compartment open model indicated that both the initial distribution space $\left(V_{1}\right)$ and the volume of distribution at steady state [Vd(ss)] of diazepam increased linearly with age $(P<0.005)$. The increase in Vd(ss) was secondary to the change in $V_{1}$. It appears then that the prolongation of $t_{i}(\beta)$ of diazepam with age is primarily dependent on an increase in the initial distribution volume of the drug. The plasma concentration/time course of the metabolite, desmethyldiazepam, was also affected by age. In older individuals, the initial presence and the peak

This study was presented in part at the annual meeting of the American Association for the Study of Liver Diseases. Chicago, October, 1973 and has appeared in abstract form (Gastroenterology. 65: 552; J. Clin. Invest. 53: 2a).

Dr. Klotz is a Fellow of the Robert-Bosch Foundation, Stuttgart, West Germany.

Received for publication 6 March 1974 and in revised form 23 September 1974. values of desmethyldiazepam were observed later and the metabolite was present in lower concentrations. Despite the profound prolongation of $t_{k}(\beta)$ with age, the constancy of diazepam clearance indicates that drug plasma concentrations will not accumulate any more in the old than the young, and chronic dosage modifications based on pharmacokinetic considerations are unnecessary.

Data obtained in patients with liver disease were compared with those found in age-matched control groups. Patients with cirrhosis showed a more than itwofold prolongation in the half-life of diazepam $(105.6 \pm 15.2$ vs. $46.6 \pm 14.2 \mathrm{~h}, P<0.001)$. This was due primarily to a decrease in the total plasma clearance of the drug in cirrhosis $(13.8 \pm 2.4$ vs. a normal of $26.6 \pm 4.1 \mathrm{ml} / \mathrm{min}, P<0.001)$. Although there was no important change in the $\mathrm{V}_{1}$ in cirrhosis $(P=0.054)$, the Vd(ss) increased significantly $(1.74 \pm 0.21$ liter $/ \mathrm{kg}$ vs. normal of $1.13 \pm 0.28 \mathrm{liter} / \mathrm{kg}, P<0.001)$ and this probably was at least partly a reflection of decreased diazepam plasma binding in cirrhosis (95.3 $\pm 1.8 \%$ vs. normal of $97.8 \pm 1.0 \%, P<0.001)$. Patients with acute viral hepatitis had a diazepam $t$ ( $\beta$ ) of $74.5 \pm 27.5 \mathrm{~h}$ and those with chronic active hepatitis of $59.7 \pm 23.0 \mathrm{~h}$, as compared to a normal value in this age group of $32.7 \pm 8.9 \mathrm{~h}(P<0.01)$. In two individuals with chronic active hepatitis who had received diazepam intravenously, the drug clearance was also depressed, 13.0 and $17.9 \mathrm{ml} / \mathrm{min}$. After recovery from acute viral hepatitis, the diazepam half-life returned almost to normal values. No statistically significant correlation was noted between the diazepam $t_{(\beta)}$ in patients with cirrhosis or hepatitis (and drug clearance in cirrhosis) and any of the standard liver function tests. The reduced clearance of diazepam in patients with acute and chronic parenchymal liver disease suggests that this drug should be used with caution, especially on a prolonged basis, in such individuals. 


\section{INTRODUCTION}

Diazepam (Valium, Roche Laboratories, Division of Hoffmann-LaRoche Inc., Nutley, N. J.) is widely used in the management of anxiety and tension, and as an anticonvulsant. Despite this extensive clinical experience, there is only limited quantitative information upon the disposition and elimination of this drug. Investigations in a variety of animal species have demonstrated that metabolism of diazepam is the predominant route of elimination (1-5). In man, the major biotransformation pathways include demethylation to $N_{1}$-desmethyldiazepam, the major metabolite detectable in the plasma, and, to a lesser extent, hydroxylation to form $N_{1}$-methyloxazepam. These two metabolites are hydroxylated and $N$-demethylated, respectively, to form oxazepam. The hydroxylated metabolites are then conjugated to their respective glucuronides, with oxazepam glucuronide as the major urinary product (1-5). Most studies of the plasma elimination of diazepam have been limited to data obtained after oral administration of the drug, particularly after prolonged therapy. Such estimates of the half-life of diazepam in normal volunteers and psychiatric patients range from 9 to $35 \mathrm{~h}(1,5-8)$. In a recent study (9), published since the present investigation was completed, the mean terminal half-life in four subjects after a single intravenous injection of the drug was found to be $33 \mathrm{~h}$.

The major involvement of the liver in the above metabolism of diazepam $(10,11)$ would suggest that hepatic dysfunction might alter the drug's disposition and elimination, as reported for other extensively metabolized drugs (12-20). Such a finding would be contrary to the general clinical impression that diazepam is a safe therapeutic agent, and a sedative of choice in patients with liver disease, a concept based on the observations that there is no prolongation of the sedative effect or abnormality in the electroencephalographic pattern in such individuals after the administration of a single dose of the drug (21). Accordingly, the present study was designed to investigate the influence of acute and chronic parenchymal liver disease on the disposition and elimination of diazepam. During this investigation it became apparent that in normal subjects, age might be a significant factor in these processes. To elucidate this, the pharmacokinetics of diazepam in normal adult human subjects were also studied, with particular emphasis upon any changes that might be associated with aging alone.

\section{METHODS}

Control and patient material. In investigating the disposition of diazepam in normal subjects, a total of 33 healthy adults ( 27 men, 6 women) with normal laboratory values and ranging in age from 15 to $82 \mathrm{yr}$ were studied. 13 individuals were classified as heavy cigarette smokers (more than 20 cigarettes/day), whereas the remaining subjects were all nonsmokers.

A total of 21 patients with liver disease, diagnosed by appropriate clinical and biochemical criteria and confirmed in 13 individuals by percutaneous liver biopsy (Table I), were also studied. Nine male patients (age $45.7 \pm 3.7 \mathrm{yr}$, mean $\pm S D$ ) had alcoholic cirrhosis, eight patients (four men, four women; age $26.1 \pm 4.1 \mathrm{yr}$ ) were diagnosed as having acute viral hepatitis, and four men (age 30.0 \pm 12.7 yr) had chronic active hepatitis. At the time of the study, the patients with alcoholic cirrhosis and chronic active hepatitis appeared clinically and biochemically stable. Each individual had received multivitamins and was ingesting a nutritionally adequate diet. Patients with acute viral hepatitis were studied during the early stage of their disease. Additionally, in five such patients, liver function tests were performed at least once weekly and the diazepam study was repeated immediately after the total serum bilirubin and serum glutamic oxaloacetic transaminase values became normal. Renal function was normal in all of the patients with liver disease.

Appropriate age-matched control groups for patients with liver disease were constructed from the data obtained in the normal subjects. 13 individuals (age $44.1 \pm 6.7 \mathrm{yr}$ ) served as controls for the alcoholic cirrhotic group, whereas 8 subjects (age 25.2 $\pm 4.0 \mathrm{yr}$ ) were used for the patients with hepatitis.

Informed consent was obtained from all participants in the studies. In all of the controls, and, unless otherwise stated (Table I), in the patients with liver disease, neither drugs nor alcohol were taken for at least $3 \mathrm{wk}$ before the investigation.

Clinical protocol. Diazepam $(0.1 \mathrm{mg} / \mathrm{kg})$ was administered intravenously into an antecubital vein over a 2 -min period to 20 normal individuals ( 17 men, 3 women), 9 patients with alcoholic cirrhosis, and 2 patients with chronic active hepatitis. Two of the above normal men, the remainder of the normal subjects, and other patients with liver disease received $10 \mathrm{mg}$ diazepam in tablet form orally after an overnight fast. Commencing $15 \mathrm{~min}$ after drug administration, heparinized venous blood samples from an antecubical vein were collected frequently from all subjects over the first few hours, and then every $12 \mathrm{~h}$ for 3 days in the normal subjects and for 4 days in the diseased patients. In two normal subjects (one after intravenous and the other after oral administration) and one patient with acute viral hepatitis, urine was collected at 12-h intervals for 2 days. Additionally, bile was collected every $6 \mathrm{~h}$ for 3 days via a biliary T-tube from a postcholecystectomy patient with normal liver function, after the oral administration of $10 \mathrm{mg}$ diazepam. The plasma binding of diazepam and desmethyldiazepam was determined for each individual subject, by using a pre-study plasma sample to which the drugs had been added to give each a concentration of $100 \mathrm{ng} / \mathrm{ml}$, by equilibrium dialysis according to a procedure similar to that described by Evans, Nies, and Shand (22). Additionally, the blood/plasma concentration ratios of the two drugs were directly determined, without correction for differences in hematocrit, from either the 16- or the 24-h blood sample.

Animal studies. Desmethyldiazepam is the major metabolite of diazepam present in the plasma. This drug is not available for human investigation. Therefore, to investigate the effect of liver damage on the elimination of desmethyldiazepam, studies were carried out in rats in which hepatic 
TABLE I

Clinical and Hepatic Function Characteristics of Patients with Cirrhosis and Viral Hepatitis

\begin{tabular}{|c|c|c|c|c|c|c|c|c|c|}
\hline Patients & $\begin{array}{l}\text { Age/ } \\
\text { weight }\end{array}$ & $t_{1}(\beta)$ & $\begin{array}{c}\text { Total } \\
\text { bilirubin }\end{array}$ & $\begin{array}{l}\text { Alkaline } \\
\text { phosphatase }\end{array}$ & $\begin{array}{l}\text { Plasma } \\
\text { albumin }\end{array}$ & SGOT & $\mathrm{LDH}$ & $\begin{array}{c}\begin{array}{c}\text { Prothrombin } \\
\text { time }\end{array} \\
\text { Patient/control }\end{array}$ & Other drugs \\
\hline Cirrhosis & $y r / k g$ & $h$ & $m g / 100 m l$ & $I U / m l$ & $\mathrm{~g} / 100 \mathrm{ml}$ & Karmen $U / m l$ & $I U / m l$ & $s$ & \\
\hline C. T.*¥ & $47 / 78.5$ & 132.6 & 1.3 & 92 & 4.1 & 40 & 170 & $12.5 / 12.0$ & - \\
\hline C. E.*‡ & $49 / 71.8$ & 120.7 & 0.7 & 120 & 3.4 & 21 & 148 & $13.4 / 11.4$ & - \\
\hline E. T.*‡ & $41 / 62.3$ & 112.3 & 2.0 & 104 & 2.5 & 64 & 200 & $15.9 / 11.4$ & - \\
\hline V. V.*‡ & $41 / 75.5$ & 104.7 & 1.6 & 128 & 3.3 & 55 & 127 & $13.4 / 11.9$ & - \\
\hline W. C.*‡ & $42 / 57.0$ & 103.0 & 1.0 & 228 & 4.4 & 44 & 50 & $13.5 / 12.0$ & - \\
\hline J. S. $\ddagger$ & $50 / 81.4$ & 101.6 & 3.2 & 138 & 3.3 & 49 & 193 & $15.6 / 11.9$ & - \\
\hline C. E.*‡ & $48 / 65.5$ & 120.7 & 1.6 & 151 & 3.1 & 44 & 130 & $11.4 / 11.9$ & - \\
\hline C. P.‡ & $44 / 84.0$ & 96.8 & 2.8 & 151 & 3.0 & 104 & 198 & $15.4 / 11.9$ & - \\
\hline C. M.*t & $49 / 55.0$ & 79.1 & 3.4 & 160 & 3.4 & 58 & 195 & $10.9 / 12.0$ & - \\
\hline \multicolumn{10}{|c|}{ Acute viral hepatitis } \\
\hline M. C. & $31 / 78.5$ & 94.2 & 15.4 & 97 & 4.5 & 1,290 & 525 & $12.0 / 11.0$ & Trimethobenzamide \\
\hline J. B.* & $30 / 60.8$ & 48.8 & 7.6 & 180 & 3.4 & 297 & 224 & $10.9 / 12.8$ & - \\
\hline B. $\mathrm{s}$. & $29 / 62.3$ & 70.0 & 5.3 & 123 & 3.9 & 1,100 & 250 & $11.5 / 11.0$ & Aspirin, propoxyphene \\
\hline к. J. & $24 / 62.3$ & 47.8 & 6.2 & 107 & 3.8 & 3,025 & 500 & $13.0 / 12.5$ & $\begin{array}{l}\text { Diphenhydramine, } \\
\text { diphenoxylate }\end{array}$ \\
\hline J. M. & $26 / 76.5$ & 64.8 & 3.8 & 85 & 4.0 & 1,020 & 330 & $12.5 / 12.5$ & - \\
\hline J. J.* & $25 / 46.0$ & 89.3 & 13.3 & 68 & 2.6 & 2,350 & - & $13.5 / 11.0$ & $\begin{array}{l}\text { Oral contraceptive, } \\
\text { promethazine }\end{array}$ \\
\hline J. H. & $26 / 80.0$ & 59.6 & 7.3 & 91 & 4.3 & 1,620 & 407 & $11.0 / 11.9$ & - \\
\hline M. S. & $18 / 48.0$ & 129.2 & 3.1 & 59 & 4.4 & 2,250 & 425 & $12.0 / 12.5$ & - \\
\hline \multicolumn{10}{|c|}{ Chronic active hepatitis } \\
\hline J. S.*ł & $24 / 73.9$ & 76.0 & 5.5 & 106 & 4.1 & 1,950 & 425 & $13.5 / 12.0$ & - \\
\hline H. C.* & $49 / 66.4$ & 70.4 & 1.3 & 179 & 2.6 & 26 & 134 & $14.5 / 11.9$ & $\begin{array}{l}\text { Spironolactone, } \\
\text { chloral hydrate, } \\
\text { pentazocine }\end{array}$ \\
\hline R. M.* & $23 / 57.8$ & 25.7 & 1.2 & 100 & 4.2 & 242 & 178 & $14.4 / 11.8$ & $\quad-$ \\
\hline K. S. *¥ & $24 / 56.0$ & 66.7 & 4.9 & 237 & 4.0 & 2,110 & 292 & $11.3 / 12.4$ & Pentazocine \\
\hline
\end{tabular}

Normal upper limits for these liver function tests are given in Table IV. The lower limit of normal for serum albumin is $3.5 \mathrm{~g} / 100 \mathrm{ml}$. SGOT, serum glutamic oxaloacetic transaminase; $\mathrm{LDH}$, lactate dehydrogenase. * Diagnosis confirmed by liver biopsy.

$\ddagger$ Diazepam given intravenously.

morphology and function were altered by pretreatment with carbon tetrachloride $\left(\mathrm{CCl}_{4}\right)$ or by bile duct ligation $(23)$. Male, nonfasted Sprague-Dawley rats (200-250 g) were given $\mathrm{CCl}_{4}(0.6 \mathrm{ml} / \mathrm{kg})$ by gavage or underwent common bile duct ligation; appropriate control rats received saline or were sham-operated, respectively. Desmethyldiazepam was administered intraperitoneally $24 \mathrm{~h}$ after the above procedures as a polyethylene glycol 300 solution $(2.5 \mathrm{mg} / \mathrm{kg}$ in $0.5 \mathrm{ml}$ ). At 30 -min intervals the animals were anesthetized and heparinized blood was collected by aortic puncture.

Analytical measurements. The concentrations of diazepam and desmethyldiazepam in the various biological fluids were determined by a gas chromatographic procedure modified from the method of de Silva and Puglisi (24). To a $0.05-1.0-\mathrm{ml}$ sample were added $1 \mathrm{ml} 0.067 \mathrm{M}$ phosphate buffer, $\mathrm{pH} 7.4$, and $1 \mu \mathrm{g}$ medazepam (internal standard) in $50 \mu \mathrm{l} 95 \%$ ethanol. The solution was extracted with $5 \mathrm{ml}$ freshly distilled diethyl ether, which, after centrifugation, was transferred to a tube containing $2 \mathrm{ml} 1 \mathrm{~N} \mathrm{HCl}$. After extraction, the ether phase was discarded, the aqueous phase washed with ether, made alkaline with $1 \mathrm{ml} 2.5 \mathrm{~N}$ $\mathrm{NaOH}$, and then extracted with $5 \mathrm{ml}$ freshly distilled ether. The ether was transferred to a $10-\mathrm{ml}$ centrifuge tube and concentrated to about $20-50 \mu 1$ in a water bath maintained at $45^{\circ} \mathrm{C}$. About $2 \mu 1$ of the ether concentrate was injected into the gas chromatograph. All samples were run in duplicate and averaged.

A Varian gas chromatograph, Model 2100, equipped with a tritium electron capture detector was used (Varian Associates, Palo Alto, Calif.). The column was Pyrex glass, $1 \mathrm{~m} \times 2 \mathrm{~mm} \times \frac{1}{4}$ in, packed with $1.5 \%$ OV-17 coated on Chromosorb G, 100/120 mesh (Johns-Manville Products Corporation, New York). Operating conditions were: oven temperature, $245^{\circ} \mathrm{C}$; injector temperature, $260^{\circ} \mathrm{C}$; detector oven temperature, $250^{\circ} \mathrm{C}$, and nitrogen flow rate, $40 \mathrm{ml} / \mathrm{min}$.

The concentrations of diazepam and desmethyldiazepam were obtained by calculating the ratio of peak heights of the drugs to that of the internal marker and relating this to previously constructed linear calibration curves over the concentration range of $1-50 \mathrm{ng} / \mathrm{ml}$. All reagents were prepared with double-distilled water and the glassware was allowed to stand overnight in chromic acid before being washed.

Pharmacokinetic and statistical calculations. After rapid intravenous injection, the diazepam plasma concentration declined biphasically and could be fitted by the exponential time function, $C_{p(t)}=A e^{-\alpha t}+B e^{-\beta t}$, where $C_{p(t)}$ is the plasma concentration at time $t, A$ and $B$ are constants, and $\alpha$ and $\beta$ are the rapid and slow exponential disposition constants, with appropriate half-lives $t_{\frac{1}{1}}(\alpha)$ and $t_{\frac{1}{2}}(\beta)$, respec- 


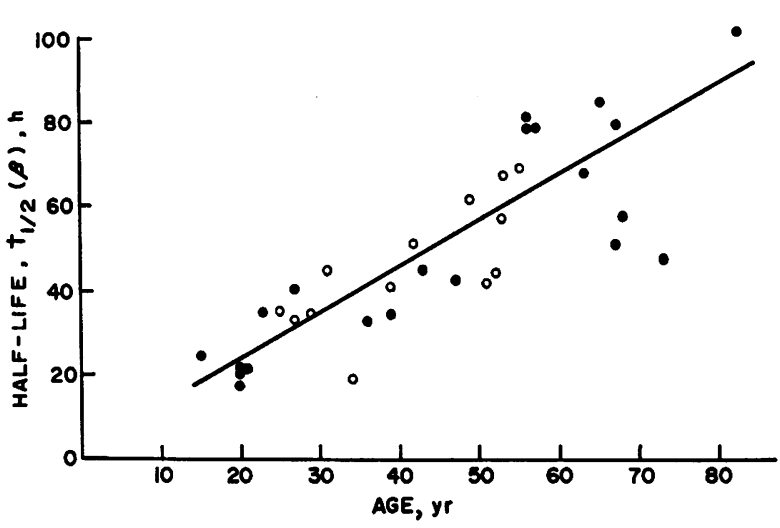

FIGURE 1 Correlation of diazepam $t_{t}(\beta)$ and age. Each symbol represents a separate study in 33 normal individuals (see Methods). Solid circles refer to nonsmokers and open circles to smokers (more than 20 cigarettes per day). Statistical details of the least sum-squares regression line are given in Table II.

tively (25). Therefore, the data for each subject were analyzed, after weighting by a coefficient of variation of 0.05 , according to a two-compartment open model and by a modified version of the least squares iterative digital computer program SAAM-23 (26). The kinetics of this model and definitions of the characteristic parameters have been well described $(25,27)$. Briefly, diazepam is considered to distribute almost instantaneously into an initial distribution space $\left(V_{1}\right),{ }^{1}$ consisting of the blood and some well-perfused/ partitioning tissues, which may be estimated after rapid intravenous injection from the relationship $V_{1}=$ dose $/ C p(0)$ (28). Irreversible elimination occurs from this compartment and may be characterized by the first-order rate constant $k_{13}$. Drug also reversibly distributes into a peripheral tissue space, consisting of the more slowly equilibrating tissues, and represented by the first-order rate constants $k_{18}$ and

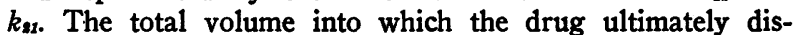
tributes, i.e. $V_{1}$ plus the peripheral tissues, is often characterized by an apparent volume of distribution, estimated by

${ }^{1}$ Abbreviations used in this paper: $t_{3}(\beta)$, terminal plasma half-life; $\mathrm{V}_{1}$, initial distribution space; $\mathrm{Vd}(\mathrm{ss})$, volume of distribution at steady state.

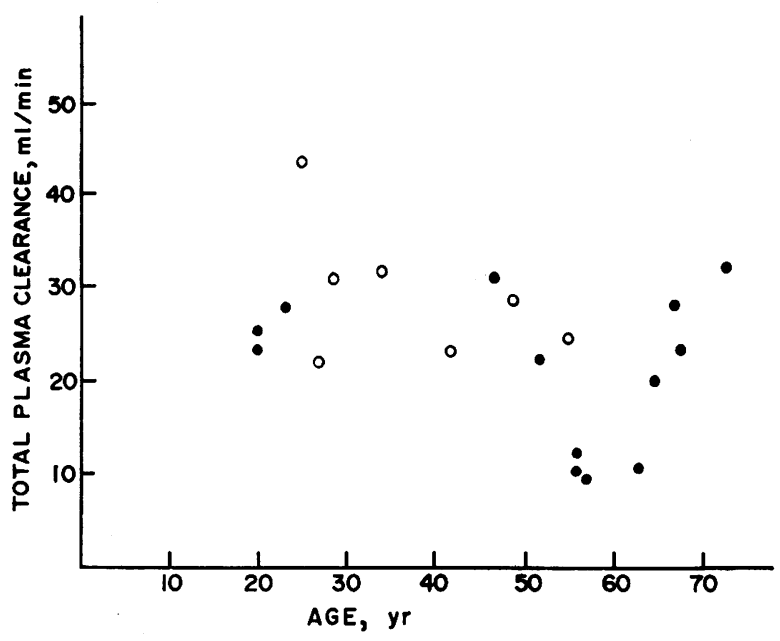

Figure 2 Relationship of total plasma clearance of diazepam with age. Each symbol represents a single normal individual. Solid circles refer to nonsmokers and open circles to smokers. Statistical details are given in Table II.

extrapolating the terminal portion of the logarithm of the plasma concentration/time curve to zero time and dividing this intercept into the dose of drug administered. However, such a procedure provides a biased estimate of distribution, since it is a function of the elimination process $(27,28)$. A better assessment of the purely distributive property of diazepam is provided by the volume of distribution at steadystate ( $\mathrm{Vd}(\mathrm{ss}))$. This parameter is dependent only upon $\mathrm{V}_{1}$ and the distribution constants $\left(\mathrm{Vd}_{(\mathrm{s} s)}=\mathrm{V}_{1}\left[1+\left(k_{18} / k_{n 1}\right)\right]\right)$ and may be regarded as the volume of distribution that would be attained if the drug were intravenously infused until steady state were attained (29). In the above kinetic model the slow disposition constant $(\beta)$, or its half-life $\left(t_{i}(\beta)\right)$, is a true measurement of the overall rate of removal of diazepam from the body. It is, however, dependent on the quantitative manner in which the drug distributes in the body, i.e., the values of $k_{13}$ and $k_{21}(25)$, and therefore the half-life does not solely reflect the elimination process. The elimination constant $k_{1 s}$ is also a function of drug distribution as indicated by the relationship $k_{x s}=$ clearance/ $V_{1}$, where clearance refers to the total volume of plasma from which drug is irreversibly removed in unit time. It

TABLE II

Stalistical Analysis of Linear Regression of Diazepam's Pharmacokinetic Parameters

\begin{tabular}{|c|c|c|c|c|c|}
\hline Parameters & $\boldsymbol{n}$ & $\begin{array}{l}\text { Slope of } \\
\text { regression }\end{array}$ & $\begin{array}{l}\text { Intercept of } \\
\text { regression }\end{array}$ & $\begin{array}{l}\text { Correlation } \\
\text { coefficient }\end{array}$ & $\begin{array}{c}\text { Statistical } \\
\text { significance }\end{array}$ \\
\hline $\mathbf{t}_{\mathbf{z}(\beta)}$ vs. age, all subjects & 35 & 1.085 & 1.98 & +0.83 & $P<0.001$ \\
\hline$t_{(\beta)}$ vs. age, nonsmokers & 22 & 1.094 & 2.26 & +0.83 & $P<0.001$ \\
\hline$t_{\text {t }(\beta)}$ vs. age, smokers & 13 & 0.977 & 5.34 & +0.76 & $P=0.003$ \\
\hline$V_{1} / \mathrm{kg}$ vs. age & 16 & 0.0061 & 0.08 & +0.70 & $P=0.003$ \\
\hline$V d_{(s e)} / \mathrm{kg}$ vs. age & 16 & 0.0172 & 0.42 & +0.74 & $P<0.001$ \\
\hline$k_{12} / k_{21}$ vs. age & 16 & 0.0032 & 2.75 & -0.05 & $P=0.848$ \\
\hline$k_{13}$ vs. age & 16 & 0.0012 & 0.1226 & -0.76 & $P<0.001$ \\
\hline Clearance vs. age & 20 & -0.186 & 32.52 & -0.39 & $P=0.089$ \\
\hline$\%$ plasma binding vs. age & 30 & -0.0002 & 97.32 & +0.003 & $P=0.986$ \\
\hline Blood/plasma ratio vs. age & 16 & 0.0047 & 0.38 & +0.54 & $P=0.546$ \\
\hline
\end{tabular}



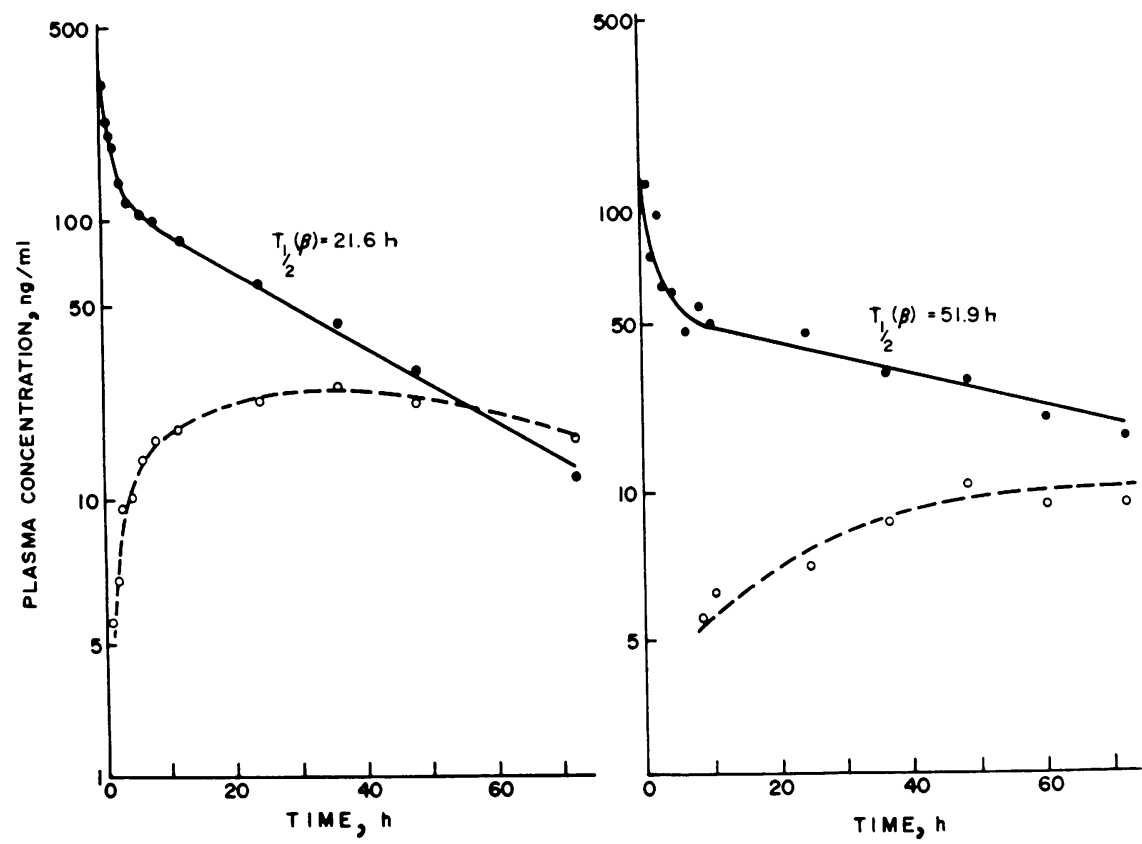

FIGURE 3 Plasma concentration/time profiles of diazepam and desmethyldiazepam after intravenous diazepam $(0.1 \mathrm{mg} / \mathrm{kg})$. The left panel shows a young normal individual $(\mathrm{K}$. $\mathrm{H}$., age $20 \mathrm{yr}$ ) and the right panel an old normal subject (M. H., age $67 \mathrm{yr}$ ). The solid lines refer to diazepam and the dashed lines to desmethyldiazepam.

is this latter term, the total plasma clearance, that provides the best estimate of the body's efficiency to remove diazepam. Furthermore, total clearance is a model-independent parameter (30), calculable after intravenous drug administration as the ratio of the injected dose to the area under the plasma or blood concentration/time curve from zero to infinite time. In the present study, good agreement was observed between this estimate and that from the product of the best-fit model parameters $k_{1 s}$ and $V_{1}$, and only the latter estimates are reported.

In four of the intravenous studies in normal subjects, the data were sufficient only to define the terminal or $\beta$-phase

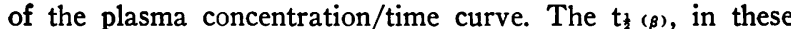
cases, and in all of the oral studies, was estimated by linear regression analysis of the logarithm of the plasma concentration/time curve. Statistical analysis of all studies was performed by the two-tailed Student $t$ test, with $P=0.05$ as the minimal level of significance.

\section{RESULTS}

\section{Effect of age}

After both intravenous and oral administration, and subsequent to the distributive and absorptive phases, respectively, the plasma concentration of diazepam declined monoexponentially. The half-life of this process $\left(t_{f}(\beta)\right)$ showed a striking age dependence ranging from about $20 \mathrm{~h}$ at $20 \mathrm{yr}$ to about $90 \mathrm{~h}$ at $80 \mathrm{yr}$ (Fig. $1)$. The precise characteristics of this relationship are not clear; however, linear regression analysis shows a highly significant correlation coefficient (Table II). Co- variant analysis, adjusted for age, showed no significant difference $(P>0.05)$ between those subjects who smoked cigarettes and those who did not (Fig. 1, Table II). No significant relationship could be discerned between age or cigarette smoking and plasma clearance of diazepam (Fig. 2, Table II). The majority of subjects exhibited clearance values in the rarge of $20-32 \mathrm{ml} / \mathrm{min}$, although one individual had a value of $43 \mathrm{ml} / \mathrm{min}$. There were, however, four subjects aged 56-63 yr who had an almost twofold smaller clearance than the other individuals. As indicated earlier, plasma concentrations of diazepam declined smoothly and biexponentially in all subjects after in travenous injection (Fig. 3), allowing analysis of the data according to the two-compartment open system, and providing an explanation for the above findings. Both $V_{1}$ and $V d(s s)$ showed a significant age dependence, whether calculated as absolute volumes or corrected for body weight (Fig. 4, Table II). The change in $\mathrm{Vd}(\mathrm{s})$ appeared to be a result of the change in $\mathrm{V}_{1}$ rather than of any age effect upon the peripheral tissue distribution constants, since a constant ratio existed between the two volumes (Table II). In the model, clearance is identified as the product, $k_{1 s} \mathrm{~V}_{1}$, and, in view of the constancy of this measurement with age, and the increase in $V_{1}$, it was not surprising to find a significant decrease in the value of the rate constant $k_{1 s}$ with age (Fig. 5, Table II). 

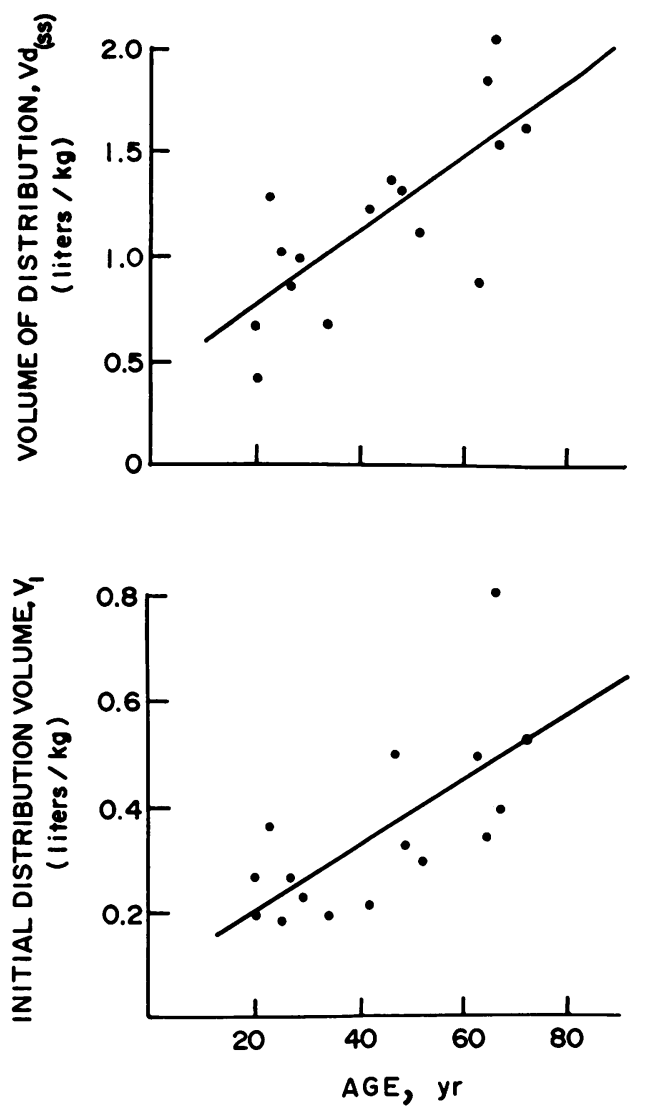

FIGURE 4 Correlation of volumes of distribution of diazepam and age in normal individuals. Each symbol refers to an individual study and statistical details of the least sumsquares regression lines are given in Table II.

The metabolite, desmethyldiazepam, was detected in the plasma of all subjects, and its time course was dependent upon the age of the subject. In the younger individuals the metabolite was first detected after about 1-2 $\mathrm{h}$. It rose slowly to reach a shallow maximum between 24 and $48 \mathrm{~h}$, and then gently declined. With increasing age the metabolite was detected later and peak concentrations were lower, and these too occurred later (Fig. 3). Since the kinetics of formation and elimination of desmethyldiazepam in man are unknown, no attempt was made to analyze pharmacokinetically plasma concentrations of this metabolite. Diazepam and desmethyldiazepam were both extensively bound to plasma constituents $(97.4 \pm 1.2 \%$, mean $\pm S D$, and 97.6 $\pm 1.3 \%$, respectively) and subjects who had a high binding of diazepam also manifested high binding of the metabolite. There was no significant effect of age upon the binding of diazepam and desmethyldiazepam or upon the blood/plasma concentration ratio of the former, $0.58 \pm 0.16$ (Table II).

After oral administration of $10 \mathrm{mg}$ diazepam, absorption was rapid and peak plasma levels of diazepam

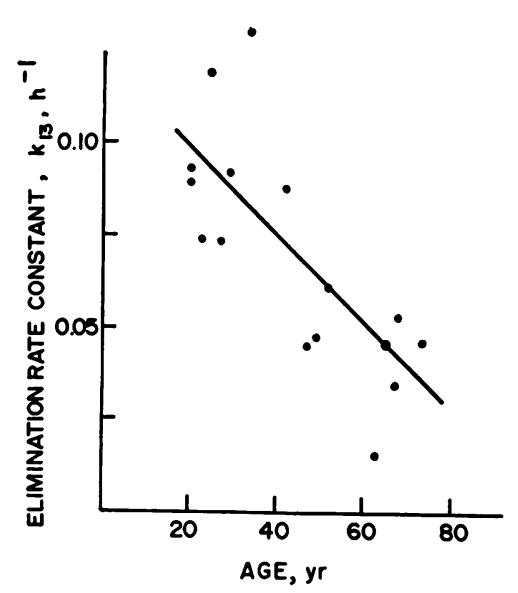

FIGURE 5 Correlation of the elimination constant, $k_{18}$, of diazepam with age in normal individuals. Each symbol refers to a single study and statistical details of the least sum-squares regression line are given in Table II.

$(221-440 \mathrm{ng} / \mathrm{ml}$ ) were observed $1 \mathrm{~h}$ after ingestion of the drug. Plasma diazepam concentrations then declined rapidly before a slower rate of change was established after about 6-9 h, i.e., an "absorption nose" was present (Fig. 6). The plasma level/time profile of desmethyldiazepam was comparable to that observed after intravenous diazepam administration. In two individuals in whom both intravenous and oral studies were carried out, the $t \frac{1}{1}(\beta)$ values were almost identical (18.2 vs. $21.1 \mathrm{~h}$ and 21.5 vs. $21.4 \mathrm{~h}$, respectively). Analysis of this data indicated that although the rate of absorption of oral diazepam was initially rapid, it was followed by a slower rate of absorption, and the bioavailability of the oral drug was only about $75 \%$. Replicate oral studies in three subjects were carried

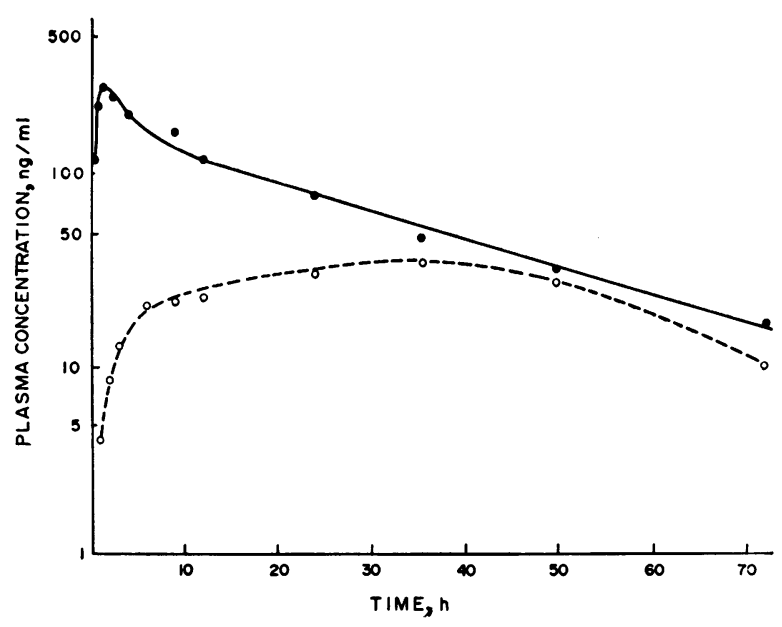

FIgURE 6 Plasma concentration/time profile of diazepam after oral administration ( $10 \mathrm{mg}$ ) to a normal subject. Solid line refers to diazepam and dashed line to desmethyldiazepam. 
out (in one subject, three experiments) with little variability in the terminal half-life.

In the two subjects from whom urine was collected, negligible amounts of unchanged diazepam ( 0.04 and $0.06 \%$ of administered dose) or desmethyldiazepam $(0.04$ and $0.10 \%)$ were excreted in the first $48 \mathrm{~h}$. Similarly, only $0.3 \%$ diazepam and $0.2 \%$ desmethyldiazepam were recovered over a $72-\mathrm{h}$ period in bile from the patient with a T-tube.

\section{Effect of liver diseases}

Cirrhotic patients. The rapid intravenous injection of diazepam in cirrhotic individuals produced qualitative plasma concentration/time profiles for diazepam and desmethyldiazepam like those observed in the normal control subject; diazepam concentrations declined biexponentially while the metabolite accumulated slowly in the plasma (Fig. 7). There were, however, significant quantitative differences between the two groups (Table III). Analysis of the diazepam data according to the two-compartment open model indicated a more than twofold prolongation in the $t_{\frac{1}{2}(\beta)}$ of this drug in alcoholic cirrhotics compared to age-matched control subjects $(105.6 \pm 15.2 \mathrm{~h}$ vs. $46.6 \pm 14.2 \mathrm{~h}, P<0.001$, Fig. 8). In the cirrhotics there was an increase of borderline significance $(P=0.054)$ in the initial distribution volume $\left(V_{1} / \mathrm{kg}\right)$ of diazepam but a highly significant increase $(P<0.001)$ in the $\mathrm{Vd}(\mathrm{ss}) / \mathrm{kg}$. These distributional changes were not, however, primarily responsible for the increase in diazepam's $t_{\frac{1}{2}(\beta)}$ in cirrhosis, since such patients also manifested a twofold decrease in the total plasma clearance (13.8 \pm 2.4 vs. $26.6 \pm 4.1 \mathrm{ml} / \mathrm{min}$ ), and accordingly, a significant decrease in the first-order elimination rate constant, $k_{1 s}$, of the drug $\left(0.030 \pm 0.001\right.$ vs. $0.075 \pm 0.030 \mathrm{~h}^{-1}$, Table III). Plasma binding of diazepam was lower in the cirrhotic group. However, this did not cause any change in the blood/plasma drug concentration ratio. $P>0.05$ (Table III). Accordingly, the calculated blood clearance of diazepam decreased to the same degree as the plasma clearance in alcoholic cirrhosis (24.8 \pm 12.7 vs. $44.8 \pm 9.1 \mathrm{ml} / \mathrm{min}, P=0.022$, Table III).

Plasma levels of the metabolite, desmethyldiazepam, were detectable in normal age-matched subjects within 2-3 h after administration of diazepam and rose to a maximum level after $35.3 \pm 8.0 \mathrm{~h}$. In alcoholic cirrhotics, there was a delay in the initial appearance of the metabolite $(3-8 \mathrm{~h})$ and peak concentrations were not attained until much later, $103.5 \pm 26.4 \mathrm{~h}$. In fact, in some cases the concentration of desmethyldiazepam was still rising at the end of the study (4 days). Although the peak concentrations attained in the cirrhotics was not statistically different from the values observed in normal subjects, there was a trend towards lower values in these patients.

Hepatitis patients. The data collected in the majority of the patients with hepatitis permitted calculation of only the $t$ ( $\beta$ ) of diazepam. A significant prolongation of this parameter was observed in both patients with acute viral hepatitis $(74.5 \pm 27.5 \mathrm{~h})$ and chronic active hepatitis $(59.7 \pm 23.0 \mathrm{~h})$ as compared to the values obtained in age-matched controls (32.7 \pm 8.9 h) (Fig. 8). Some of the patients with hepatitis had previously received other drugs, usually only as a single dose (Table I), but no difference in the half-life of diazepam was discernible between these individuals and those patients who were free of other drugs $(P>$ $0.05)$. In the two patients with chronic active hepatitis who were administered diazepam intravenously, the increase in $t_{\frac{1}{3}(\beta)}$ was associated with a reduction in plasma clearance of the drug to 13.0 and $17.9 \mathrm{ml} / \mathrm{min}$, respectively.

In the five patients with acute viral hepatitis, who were followed periodically during recovery, the study was repeated later, when the hepatic function tests had just returned into the normal range. In all subjects the elimination of diazepam was faster at recovery than in the active phase of the disease (Table IV), but the $t_{1}(\beta)$ was still prolonged relative to the range (mean $\pm S D$ ) observed in normal subjects. In patient $J . H$. the reduction in the half-life was initially minimal but 4 mo later the $t_{1}(\beta)(33.0 \mathrm{~h})$ was within the normal range. The fraction of the administered dose excreted in the urine as diazepam or desmethyldiazepam in the single patient with acute viral hepatitis was negligible and comparable to the results observed in normal subjects.

In patients with alcoholic cirrhosis there was no statistical correlation between diazepam $t_{(\beta)}$ or clearance and any of the routine liver function tests, and similar results were obtained with the $t$ ( $\beta$ ) in individuals with viral hepatitis.

Animal studies. In normal, bile-duct ligated, and sham-operated rats the plasma elimination of unchanged drug after intraperitoneal administration of desmethyldiazepam was rapid and identical in all three groups, $\mathrm{t}_{(\beta)}=1.7 \mathrm{~h}$. However, rats with $\mathrm{CCl}_{4}$-induced liver damage exhibited a prolonged $t_{i}(\beta)(3.6 \mathrm{~h}, P<$ 0.005 ).

\section{DISCUSSION}

The first major finding in this study is the demonstration of a four-to-five-fold increase in diazepam half-life $\left(t_{1}(\beta)\right)$ with increasing age (Fig. 1). Information on age-induced changes in drug disposition and elimination in man is limited, despite the observations that elderly patients often exhibit an apparent sensi- 

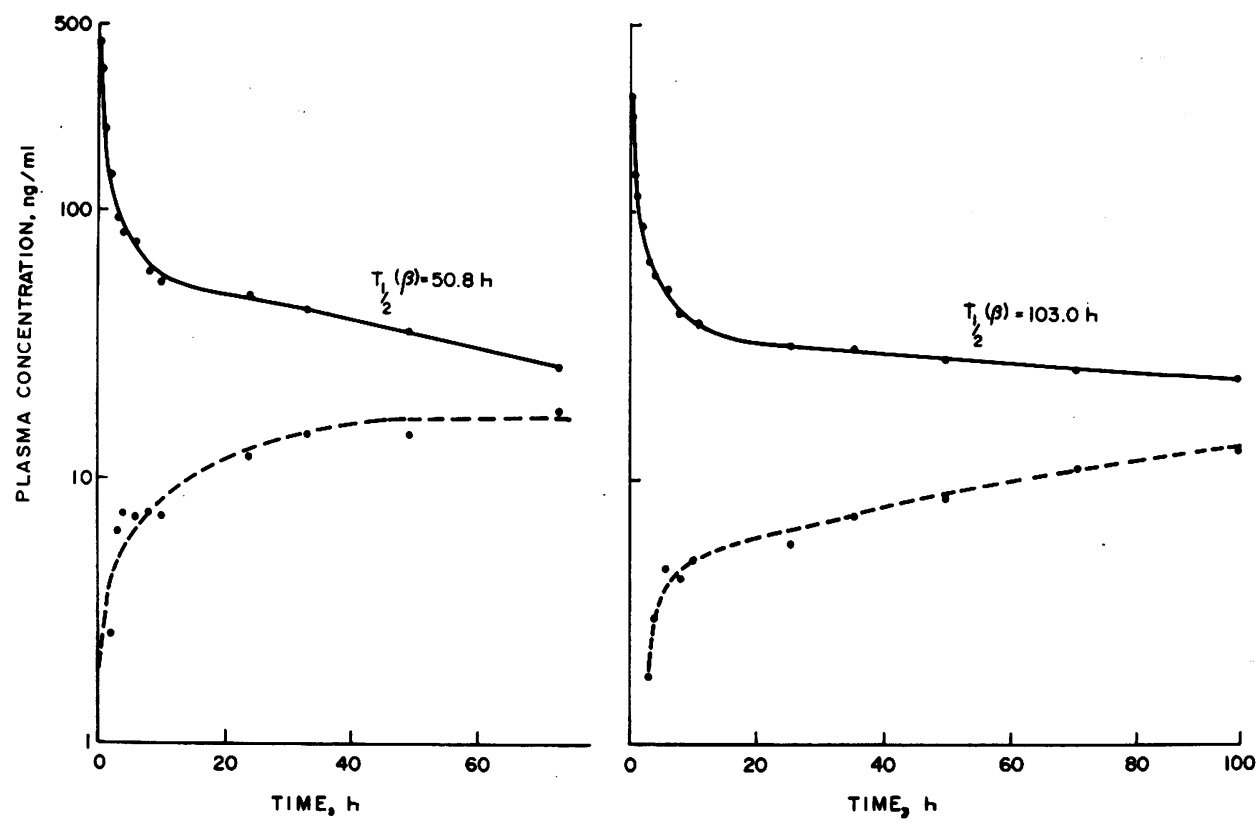

Figure 7 Plasma concentration/time profile for diazepam (solid line) and desmethyldiazepam (dashed line) after rapid intravenous injection of diazepam $(0.1 \mathrm{mg} / \mathrm{kg})$. The left panel shows a representative normal age-matched control subject and the right panel, a typical patient with alcoholic cirrhosis.

tivity to various therapeutic agents $(31,32)$. Modest increases in the plasma half-life of antipyrine (33), phenylbutazone (33), and aminopyrine (34) in older individuals have been reported previously. These findings were felt to represent a decrease of hepatic drug metabolism similar to that observed in the rat (35, 36). Such an impairment should manifest iteself as a reduction in the metabolic clearance of the drug and,

\section{TABLE III}

Pharmacokinetic Parameters of Diazepam in Normal Age-Malched Control and Alcoholic Cirrhotic Subjects (mean $\pm S D$ )

\begin{tabular}{|c|c|c|c|}
\hline Parameter & $\begin{array}{c}\text { Normal } \\
n=5^{*}\end{array}$ & $\begin{array}{c}\text { Alcoholic } \\
\text { cirrhosis } \\
n=9\end{array}$ & $\begin{array}{c}P \\
\text { value }\end{array}$ \\
\hline$t_{1}(a), h$ & $0.82 \pm 0.23$ & $1.29 \pm 0.77$ & 0.220 \\
\hline$t(\beta), h$ & $46.6 \pm 14.2 \ddagger$ & $105.6 \pm 15.2$ & $<0.00$ \\
\hline$V_{1} / \mathbf{k g}$, liter $/ \mathbf{k g}$ & $0.31 \pm 0.12$ & $0.42 \pm 0.09$ & 0.05 \\
\hline$V d(a s) / \mathrm{kg}$, liter $/ \mathrm{kg}$ & $1.13 \pm 0.28$ & $1.74 \pm 0.21$ & $<0.00$ \\
\hline$k_{18}, h^{-1}$ & $0.075 \pm 0.035$ & $0.030 \pm 0.010$ & 0.003 \\
\hline Plasma clearance, $m l / m i n$ & $26.6 \pm 4.1$ & $13.8 \pm 2.4$ & $<0.00$ \\
\hline Blood clearance, $\mathrm{ml} / \mathrm{min}$ & $44.8 \pm 9.1$ & $24.8 \pm 12.7$ & 0.022 \\
\hline \multicolumn{4}{|l|}{ Blood/plasma } \\
\hline concentration ratio & $0.58 \pm 0.15$ & $0.62 \pm 0.20$ & 0.720 \\
\hline Plasma binding, $\%$ & $97.8 \pm 1.08$ & $95.3 \pm 1.8$ & $<0.001$ \\
\hline
\end{tabular}

* Due to plasma sampling times, detailed pharmacokinetic calculations were possible in only 5 of the 13 controls in whom diazepam was administered intravenously.

$\ddagger n=13$.

$8 n=11$. if urinary and biliary drug excretion are negligible, as with diazepam, this decrease should be directly reflected in the total plasma clearance. However, since in $80 \%$ of our subjects no such reduction in clearance was observed over the age range studied, the increase in $t_{f}(\beta)$ cannot be attributed to any age-dependent im-
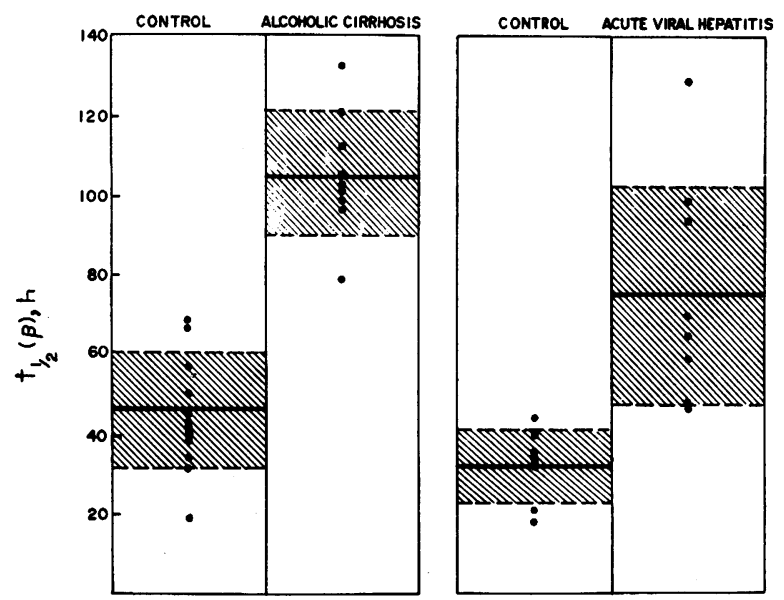

FIGURE 8 Comparison of the $t(\beta)$ of diazepam in patients with alcoholic cirrhosis and acute viral hepatitis, and their age-matched controls. Each point represents an individual subject and the hatched area indicates the mean $\pm S D$. The $t_{1}(\beta)$ values in both the cirrhotic and acute viral hepatitis groups were significantly longer $(P<0.001)$ than in the corresponding age-matched control groups. 
TABLE IV

Correlation between Hepatic Function Tests and $t_{\mathbf{z}(\beta)}$ of Diazepam in the Same Patients at Time of Acute Viral Hepatitis and at Recovery

\begin{tabular}{|c|c|c|c|c|c|c|}
\hline Subject & $t y(\beta)$ & Bilirubin & LDH & SGOT & $\begin{array}{c}\text { Alkaline } \\
\text { phosphatase }\end{array}$ & Albumin \\
\hline & $h$ & $m g / 100 m l$ & $I U / m l$ & Karmen $U / m l$ & $I U / m l$ & $\mathrm{~g} / 100 \mathrm{ml}$ \\
\hline B. S.* & 70.8 & 5.3 & 250 & 1,100 & 123 & 3.9 \\
\hline B. S.f & 47.4 & 0.9 & 169 & 43 & 79 & 5.0 \\
\hline M. C.* & 94.2 & 15.4 & 525 & 1,290 & 97 & 4.5 \\
\hline M. C. $\ddagger$ & 62.2 & 1.0 & 150 & 30 & 42 & 4.2 \\
\hline J. H.* & 59.6 & 7.3 & 407 & 1,620 & 91 & 4.3 \\
\hline J. H. $\ddagger$ & 57.2 & 0.8 & 133 & 30 & 37 & 5.6 \\
\hline J. H. $\S$ & 36.0 & 0.3 & 167 & 12 & 40 & 5.6 \\
\hline J. M.* & 64.8 & 3.8 & 330 & 1,020 & 85 & 4.0 \\
\hline J. M.‡ & 53.3 & 1.1 & 138 & 25 & 65 & 4.8 \\
\hline J. J.* & 89.3 & 13.3 & n.a. & 2,350 & 68 & 2.6 \\
\hline J. J.‡ & 49.0 & 1.1 & 156 & 44 & 41 & 4.2 \\
\hline Upper normal limit & 45.4 & 1.0 & 200 & 40 & 85 & \\
\hline
\end{tabular}

* Acute stage.

$\ddagger$ Recovery stage.

$\$ 4$ mo after all hepatic function tests had returned to normal.

pairment of drug-metabolizing activity. On the other hand, significant alterations in the distribution of diazepam occurred with aging, in that both $\mathrm{V}_{\mathbf{1}}$ and $\mathrm{Vd}(\mathrm{ss})$ increased in a linear fashion with age (Fig. 4). Since $\mathrm{Vd}(s s)=\mathrm{V}_{1}\left[1+\left(k_{n z} / k_{s t}\right)\right]$, and there was no age-dependent alteration in the distribution ratio $k_{z} / k_{z}$ (i.e. the fractional distribution of diazepam between the initial and tissue compartments), the linear increase in $\mathrm{Vd}(\mathrm{ss})$ with age simply reflects the linear change in $V_{1 .}$. The initial distribution space is generally conceived to represent drug distribution in the blood and in the tissues that rapidly come into equilibrium with the blood, relative to the sampling times (25). The rate of drug uptake into the tissues is dependent on several parameters, including the rate of tissue perfusion with blood, the mass of tissue, and the partition characteristics of the compound between blood and tissue. The latter involves such factors as membrane permeability, intra- and extracellular $\mathrm{pH}$, and plasma and tissue drug binding. Cardiac output and tissue perfusion are both reduced with age (37), but drug distributional changes due to these alterations may well be offset by changes in the tissue distribution of the cardiac output, as well as decreases in tissue and lean body masses $(31,32)$. No. age-related differences were observed in the plasma binding of diazepam, but it is possible that tissue binding may have altered. The distribution of a drug such as diazepam is so complex that it is difficult to identify precisely the specific biological causes of the change in the kinetic findings.
In four older subjects, a significant reduction in the total plasma clearance contributed to the prolongation of diazepam half-life. Chronological age is arbitrary and does not necessarily correspond to biological age, and aging leads to an increasing divergence in drug response among individuals (31). Consequently, it is possible to speculate that these four individuals were examples of a further age-dependent phenomenon: namely, a reduction in the hepatic extraction of diazepam associated with an impairment of drug-metabolizing enzyme activity.

Although the relationship between age and $t ;(\beta)$ was linear from 20 to $80 \mathrm{yr}$, such a correlation cannot be extrapolated to younger individuals. In premature infants the half-life of diazepam is considerably prolonged, whereas young children exhibit values around $18 \mathrm{~h}$ (38). The complete lifetime temporal pattern of the drug half-life/age relationship is therefore complex and the changes probably involve multiple causative factors.

The extensive plasma binding of diazepam, shown here, has been reported previously (6). This binding may well be responsible, at least in part, for the small distribution of diazepam into the erythrocyte, as indicated by the low blood/plasma concentration ratio, similar in magnitude to that reported by Zingales (39). Plasma binding may also play an important role in the hepatic metabolism of the drug, irrespective of any distributional factors. If the normal total hepatic blood flow is equal to $1.5 \mathrm{liter} / \mathrm{min}$ (40), the estimated un- 
bound drug clearance is, within experimental error, almost equal to the diazepam blood clearance calculated from the observed plasma clearance and the blood/ plasma concentration ratio of the drug. This suggests, but not conclusively, that only the unbound diazepam present in blood delivered to the liver is extractable by the organ. Additionally, the inferred low extraction ratio for total drug would indicate a lack of effect of changes in hepatic blood flow upon the clearance of the drug (41). This type of elimination would appear to provide an alternative explanation for the long halflife of diazepam rather than enterohepatic recycling $(6,7)$ or storage in some kinetic "deep" compartment (9). The lack of significant biliary excretion also appears to reduce the contribution of this process to the erratic fluctuations in diazepam plasma concentrations that some investigators have reported (5-7), but which were not observed in the present and other studies $(8,9)$.

Recent epidemiological studies have indicated a statistical relationship between the depression of the central nervous system during chronic diazepam therapy and cigarette smoking; drug-attributed drowsiness becoming less common as the exposure to cigarette smoke increases (42). Such findings might be explained by stimulation of diazepam's metabolism by one or more of the constituents of cigarette smoke (42). Such an effect would manifest itself by an increase in the plasma clearance and by a reduction in the $t_{1}(\beta)$ of the drug, yet no obvious differences between these values in smokers and nonsmokers were seen at any age in the present study. Differences may exist in the value of the half-life after single versus multiple doses of diazepam in some individuals (9, unpublished observation) and the chronic half-life may be affected by cigarette smoking more significantly than the acute value. However, the present results suggest that factors other than inferred changes in metabolism are involved in the greater incidence of side-effects of diazepam in nonsmokers (43).

The metabolite, desmethyldiazepam, has similar (but probably weaker) pharmacological activity to the parent drug $(3,44,45)$, but lack of knowledge of its kinetics of disposition and elimination when administered per se prevented any analysis of the effect of age upon its formation, distribution, and elimination after diazepam administration. However, the lower concentrations, the delay in appearance, and the time to peak concentration of this metabolite with increasing age would be consistent with an age-dependent change in the distribution of both the metabolite and the parent drug.

The second important new observation in this study is the demonstration of a major impairment of diazepam elimination, independent of the effect of age, in drug and alcohol-free patients with alcoholic cirrhosis. Similar results were obtained in individuals with acute and chronic viral hepatitis, some of whom had received other drugs before the study. The primary cause of this prolongation of diazepam $t_{(\beta)}$ in the cirrhotics and the two patients with chronic active hepatitis, who received the drug intravenously, was a significant, twofold reduction in diazepam clearance from the blood (Table III). This process is a direct reflection of hepatic drug removal and could be the result of decreased hepatic perfusion, impaired hepatic extraction of diazepam, or both conditions. With regard to hepatic perfusion, the magnitude of drug clearance relative to total liver blood flow is not sufficient to suggest that changes in the latter would have an important effect on drug clearance (41). The data on diazepam's half-life in patients with acute viral hepatitis support this conclusion, since such individuals do not exhibit gross evidence of shunting of blood around the liver or decrease in hepatic blood flow (46) and yet show a major prolongation of drug $t(\beta)$. These considerations suggest that the decrease in diazepam clearance with liver disease reflects an impairment of drug extraction by the liver, which in turn is probably a result of a reduced capacity to metabolize the compound. In vitro studies with human liver biopsy samples have demonstrated a reduction in the activity of various mixedfunction oxidase systems in cirrhosis and hepatitis, although the disease had to be severe before these changes were seen $(47,48)$. In as much as hepatic extraction of diazepam in normal individuals appears to be limited to unbound drug in blood (vide supra), one might anticipate that the decreased diazepam plasma binding in cirrhosis would tend to increase and not decrease the blood clearance of the drug. Hence, the present assessment of impaired hepatic extraction of diazepam in cirrhosis may be actually an underestimation of the effect of hepatic damage on the metabolism of the drug.

The site(s) of impairment in the hepatic metabolism of diazepam were not specifically investigated in the present study; however, certain observations may be appropriate to the problem. After diazepam administration, desmethyldiazepam is the only metabolite readily detectable in the plasma. The delay in appearance, i.e. formation, of the compound and the occurrence of the peak concentration at a later time in liver disease patients would suggest that the $N$-demethylation pathway is impaired. It is likely that the subsequent hydroxylation of desmethyldiazepam is also affected, since the maximal plasma concentration of the metabolite is comparable in the diseased and control groups. The studies in rats with $\mathrm{CCl}_{4}$-induced liver damage support this suggestion. Human hepatic dis- 
ease, therefore, may produce impairment at multiple sites in the overall metabolism of diazepam, but at present supportive data exist only for the demethylation step.

The increase in $V_{1}$ of diazepam with cirrhosis was of borderline statistical significance but could have contributed to the prolongation of $t_{i}(\beta)$. This may have been a disease-related effect, but since $V_{1}$ for diazepam is also a function of age, it may reflect a less than optimal biological age-matching of control and cirrhotic individuals by chronological age alone. The increase in Vd(so) in cirrhosis was sufficiently significant, however, that a real change due to cirrhosis is likely. This may be due to the observed decrease in diazepam plasma binding, although alterations in tissue uptake and binding in cirrhosis cannot be excluded. Similar findings in patients with liver disease have been reported recently for lidocaine (14).

The lack of any significant statistical correlation between the $t_{i}(\beta)$ or plasma clearance of diazepam and any of the commonly employed biochemical tests for the assessment of liver function in the present patients is in accord with our previous findings with meperidine (15) and also with the data for lidocaine (14) and carbenicillin (17). The delay in return of diazepam's elimination to normal in all tive patients with acute viral hepatitis, in whom recovery of the biochemical parameters had been achieved, also suggests that such tests do not adequately reflect the capacity of the liver to metabolize diazepam. Serum albumin concentration and/or the prothrombin index have been shown to be good indicators for the prolongation of $t_{1}(\beta)$ of antipyrine (12), amylobarbital (13), and phenylbutazone (16), but only when these functions showed major impairment. However, these findings are of little general predictive value, especially when these parameters are within the normal range but drug disposition and elimination are significantly altered: a classification into which many of our patients could be placed. It appears, therefore, that no single test is presently capable of predicting the effect of liver disease upon a drug's elimination; each drug must be separately investigated. This is not surprising in view of the diversity in site and nature of the rate-limiting processes for the multitude of reactions carried out in the liver. Interestingly, some of the present patients with liver disease were also subjects in a similar study involving meperidine (15). In these cases good agreement was seen between the changes in elimination for the two drugs; those patients with the most impaired elimination of diazepam also had the greatest reduction in clearance of meperidine, and vice versa.

The $t_{i}(\beta)$ of diazepam after a single dose is prolonged by both aging and various types of liver disease.
However, because of the different mechanisms responsible for this prolongation, the consequences of these conditions, in relation to the clinical usage of the drug, particularly according to some fixed-interval multiple dosing schedule, are profoundly different for the two groups of individuals. During continuous therapy the drug plasma concentration accumulates at a rate proportional to $t_{i}(\beta)$, however, the final steady-state levels are controlled by the total clearance rate (49). Accordingly, the impaired clearance and prolonged $t_{\frac{1}{3}}(\beta)$ of diazepam in liver disease would suggest that after acute administration the plasma concentration of unchanged drug would be higher, and that chronic drug administration would exaggerate the difference between these patients and normal subjects receiving a standard dosage regimen. Presumably, the pharmacological effects of diazepam are related to the plasma concentration of unchanged drug, and consequently, the clinical effects would be greater in the diseased group. If the elimination of the pharmacologically active metabolites of diazepam is also impaired in these patients, then the accumulation of such compounds may further increase the sedative effect of the drug. Furthermore, any reduction in the extent of plasma drug binding would tend to exaggerate the clinical effects at any given total drug plasma level. Clearly, studies of parent drug and metabolite accumulation during chronic administration and the relationship of these levels to the clinical effects elicited are needed. Pending such investigations, it would appear prudent to use diazepam cautiously in patients with severe parenchymal liver disease.

In the aging normal subjects, where the prolongation of $t_{(\beta)}$ is due to an alteration in the distribution of the drug rather than to its clearance, a much different situation will arise if the pharmacokinetics elucidated after a single dose are applied to chronic intermittent dosing. During the dosing interval, because clearance is constant, the average steady state plasma level of diazepam will be unaffected by aging. The only effect of the prolongation of $t_{\frac{1}{2}}(\beta)$ with age will be a blunting of the fluctuation between the peak and trough drug levels at the beginning and end of the interval, respectively. In addition, steady state will be achieved more rapidly in the younger subjects than in the old individuals since this condition is achieved in approximately four times the elimination half-life (49). With aging, a greater mass of drug will also be present in the tissue compartment at a steady-state, but again since $\mathrm{Vd}_{(\mathrm{s})}$ is proportional to $\mathrm{V}_{1}$, and there is no age-dependency in the distribution ratio, $k_{z z} / k_{z 1}$, the concentration of drug in this pharmacokinetic compartment will be similar in all individuals and independent of age. The frequency of central nervous sys- 
tem side effects related to chronic diazepam administration has been noted to increase significantly between the age of 40 and 70 (42). This may reflect an increased concentration of pharmacologically active drug at the receptor site that is not revealed by the compartmental analysis of the present data. But an alternative hypothesis, consistent with other observations of drug activity in the aged (31), is that the sensitivity of the involved receptor site increases with age. Accordingly, dosage modifications for diazepam in geriatric patients cannot be based solely on the patient's disposition and elimination characteristics. Clearly more investigation is required to define adequately the mechanisms of the altered clinical responsiveness to therapeutic agents that occurs with many drugs as the individual ages $(31,32)$, the temporal pattern of any changes throughout the life of the individual, and those drugs for which such alterations are clinically relevant.

The present studies clearly demonstrate the problems involved in directly associating changes in $t_{t}(\beta)$ or a model-dependent rate constant of elimination such as $k_{18}$ with the biological processes of drug excretion and metabolism. It is essential that the mechanism(s) for the observed pharmacokinetic changes be delineated, particularly if modifications in dosage regimens are to be based on such data. For example, a lack of appreciation of the central role of the distribution volume changes in the prolongation of $t_{(\beta)}$ with aging would lead to the erroneous conclusion that greater drug concentrations would occur in older subjects maintained on the same dosage regimen as the young individuals. A greater awareness of the concept of clearance (50) and the relationship of the latter to the commonly estimated pharmacokinetic constants would do much to overcome this and similar problems associated with the application of pharmacokinetics to rational drug usage.

\section{ACKNOWLEDGMENTS}

The authors are grateful for the excellent technical assistance of Mr. Raymond F. Johnson.

This investigation was supported by U. S. Public Health Service grants 5R01 AA0267-04 and GM 15431.

\section{REFERENCES}

1. Schwartz, M. A., B. A. Koechlin, E. Postma, S. Palmer, and G. Krol. 1965. Metabolism of diazepam in rat, dog, and man. J. Pharmacol. Exp. Ther. 149: 423-435.

2. Schwartz, M. A., and E. Postma. 1968. Metabolism of diazepam in vitro. Biochem. Pharmacol. 17: 2443-2449.

3. Marcucci, F., A. Guaitani, J. Kvetina, E. Mussini, and S. Garrattini. 1968. Species difference in diazepam metabolism and anticonvulsant effect. Eur. J. Pharmacol. 4: 467-470.

4. Marcucci, F., R. Fanelli, E. Mussini, and S. Garrattini. 1970. Further studies on species difference in diazepam metabolism. Eur. J. Pharmacol. 9: 253-256.
5. de Silva, J. A. F., B. A. Koechlin, and G. Bader. 1966. Blood level distribution patterns of diazepam and its major metabolite in man. J. Pharm. Sci. 55: 692-702.

6. van der Kleijn, E., J. M. van Rossum, E. T. J. M. Muskens, and N. V. M. Rijntjes. 1971. Pharmacokinetics of diazepam in dogs, mice and humans. Acta Pharmacol. Toxicol. 29 (Suppl. 3) : 109-127.

7. van der Kleijn, E. 1971. Pharmacokinetics of distribution and metabolism of ataractic drugs and an evaluation of the site of antianxiety activity. Ann. N. Y. Acad. Sci. 179: $115-125$.

8. Berlin, A., B. Siwers, S. Agurell, A. Hiort, F. Sjöqvist, and S. Ström. 1972. Determination of bioavailability of diazepam in various formulations from steady state plasma concentration data. Clin. Pharmacol. Ther. 13: 733-744.

9. Kaplan, S. A., M. L. Jack, K. Alexander, and R. E. Weinfield. 1973. Pharmacokinetic profile of diazepam in man following single intravenous and oral and chronic oral administration. J. Pharm. Sci. 62: 1789-1796.

10. Kvetina, J., F. Marcucci, and R. Fanelli. 1968. Metabolism of diazepam in isolated perfused liver of rat and mouse. J. Pharm. Pharmacol. 20: 807-808.

11. Marcucci, F., R. Fanelli, E. Mussini, and S. Garattini. 1969. The metabolism of diazepam by liver microsomal enzymes of rats and mice. Eur. J. Pharmacol. 7 : 307313.

12. Branch, R. A., C. N. Herbert, and A. E. Read. 1973. Determinants of serum antipyrine half-lives in patients with liver disease. Gut. 14: 569-573.

13. Mawer, G. E., N. E. Miller, and L. A. Turnberg. 1972. Metabolism of amylobarbitone in patients with chronic liver disease. $\mathrm{Br}$. J. Pharmacol. 44: 549-560.

14. Thomson, P. D., K. L. Melmon, J. A. Richardson, K Cohn, W. Steinbrunn, R. Cudihee, and M. Rowland. 1973. Lidocaine pharmacokinetics in advanced heart failure, liver disease, and renal failure in humans. Ann. Intcrn. Med. 78: 499-508.

15. Klotz, U., T. S. McHorse, G. R. Wilkinson, and S. Schenker. 1974. The effect of cirrhosis on the disposition and elimination of meperidine (pethidine) in man. Clin. Pharmacol. Ther. 16: 667-675.

16. Levi, A. J., S. Sherlock, and D. Walker. 1968. Phenylbutazone and isoniazid metabolism in patients with liver disease in relation to previous drug therapy. Lancet. 1: $1275-1279$.

17. Hoffman, T. A., R. Cestero, and W. E. Bullock. 1970. Pharmacodynamics of carbenicillin in hepatic and renal failure. Ann. Intern. Med. 73: 173-178.

18. Kunin, C. M., A. J. Glazko, and M. Finland. 1959. Persistence of antibiotics, in blood of patients with acute renal failure. II. Chloramphenicol and its metabolic products in blood of patients with severe renal disease or hepatic cirrhosis. J. Clin. Invest. 38: 1498-1508.

19. Ueda, H., T. Sakurai, M. Ota, A. Nakajima, K. Kamii, and H. Maezawa. 1963. Disappearance rate of tolbutamide in normal subjects and in diabetes mellitus, liver cirrhosis, and renal disease. Diabetes. 12: 414-419.

20. Acocella, G., L. Bonollo, M. Garimoldi, M. Mainardi, L. T. Tenconi, and F. B. Nicolis. 1972. Kinetics of rifampicin and isoniazid administered alone and in combination to normal subjects and patients with liver disease. Gut. 13 : 47-53.

21. Murray-Lyon, I. M., J. Young, J. D. Parkes, R. P. Knill-Jones, and R. Williams. 1971. Clinical and electroencephalographic assessment of diazepam in liver disease. Br. Med. J. 4: 265-266. 
22. Evans, G. H., A. S. Nies, and D. G. Shand. 1973. The disposition of propranolol. III. Decreased half-life and volume of distribution as a result of plasma binding in man, monkey, dog and rat. J. Pharmacol. Exp. Ther. 186: 114-122.

23. Breen, K. J., J. Shaw, J. Alvin, G. I. Henderson, A. Hoyumpa, and S. Schenker. 1973. Effect of experimental hepatic injury on the clearance of phenobarbital and paraldehyde. Gastroenterology. 64 : 992-1004.

24. de Silva, J. A. F., and C. V. Puglisi. 1970. Determination of medazepam (Nobrium), diazepam (Valium) and their major biotransformation products in blood and urine by electron capture gas-liquid chromatography. Anal. Chem. 42: 1725-1736.

25. Riegelman, S., J. C. K. Loo, and M. Rowland. 1968. Shortcomings in pharmacokinetic analysis by conceiving the body to exhibit the properties of a single compartment. J. Pharm. Sci. 57: 117-123.

26. Berman, M., and M. F. Weiss. 1966. SAAM Manual, Public Health Service Manual No. 1703, U. S. Government Printing Office, Washington, D. C.

27. Jusko, W. J., and M. Gibaldi. 1972. Effects of change in elimination on various parameters of the two-compartment open model. J. Pharm. Sci. 61: 1270-1273.

28. Riegelman, S., J. Loo, and M. Rowland. 1968. Concept of a volume of distribution and possible errors in evaluation of this parameter. J. Pharm. Sci. 57: 128-133.

29. Perrier, D., and M. Gibaldi. 1973. Relationship between plasma or serum drug concentration and amount of drug in the body at steady state upon multiple dosing. J. Pharmacokinet. Biopharm. 1: 17-22.

30. Westlake, W. J. 1970. Time integral of drug concentration in the central (plasma) compartment. J. Pharm. Sci. 59: 722-723.

31. Bender, A. D. 1964. Pharmacologic aspects of aging: a survey of the effect of increasing age on drug activity in adults. J. Am. Geriatr. Soc. 12: 114-134

32. Bender, A. D. 1967. Pharmacodynamic consequences of aging and their implications in the treatment of the elderly patient. Med. Ann. D. C. 36: 267-271.

33. O'Malley, K., J. Crooks, E. Duke, and I. H. Stevenson. 1971. Effect of age and sex on human drug metabolism. Br. Med. J. 3: 607-609.

34. Jori, A., E. DiSalle, and A. Quadri. 1972. Rate of aminopyrine disappearance from plasma in young and aged humans. Pharmacology. (Basel). 8: 273-279.

35. Kato, R., P. Vassanelli, G. Frontino, and E. Chiesera. 1964. Variation in the activity of liver microsomal drug metabolizing enzymes in rats in relation to the age. Biochem. Pharmacol. 13: 1037-1051.

36. Kato, R., and A. Takanaka. 1968. Metabolism of drugs in old rats (II). Metabolism in vivo and effect of drugs in old rats. Jap. J. Pharmacol. 18: 389-396.

37. Bender, A. D. 1965. The effect of increasing age on the distribution of peripheral blood flow in man. J. Am. Geriatr. Soc. 13: 192-198.

38. Morselli, P. L., N. Principi, G. Tognoni, E. Reali, G. Belvedere, S. M. Standen, and F. Sereni. 1973. Diazepam elimination in premature and full-term infants and children. J. Perinatal Med. 1: 133-141.

39. Zingales, I. A. 1973. Diazepam metabolism during chronic medication unbound fraction in plasma, erythrocytes and urine. J. Chromatogr. $75: 55-78$.

40. Altman, P. L., and D. S. Dittmer. 1971. Respiration and Circulation. Biological Handbook. Federation of the American Societies for Experimental Biology, Bethesda, Md.

41. Branch, R. A., A. S. Nies, and D. G. Shand. 1973. The disposition of propranolol. VIII. General implications of the effects of liver blood flow on elimination from the perfused rat liver. Drug Metab. Disposition. 1: 687-690.

42. Boston Collaborative Surveillance Program. 1973. Clinical depression of the central nervous system due to diazepam and chlordiazepoxide in relation to cigarette smoking and age. N. Engl. J. Med. 288: 277-280.

43. Bhattacharya, I. C., L. Goldstein, and C. C. Pfeiffer. 1970. Influence of acute and chronic nicotine administration on EEG reactivity to drugs in rabbits. 2. Psychoactive agents. Res. Commun. Chem. Pathol. Pharmacol. 1: $109-114$

44. Randall, L. O., G. A. Heise, W. Schalleck, R. E. Bagdon, R. Banziger, A. Boris, R. A. Moe, and W. B. Abrams. 1961. Pharmacological and clinical studies on Valium, a new psychotherapeutic agent of the benzodiazepines class. Curr. Ther. Res. (Clin. Exp.). 3: 405425

45. Coutinho, C. B., J. A. Cheripko, and J. J. Carbone. 1970. Correlation between the duration of the anticonvulsant activity of diazepam and its physiological disposition in mice. Biochem. Pharmacol. 19: 363-379.

46. Preisig, R., J. G. Rankin, J. Sweeting, and S. E. Bradley. 1966. Hepatic hemodynamics during viral hepatitis in man. Circulation. 34: 188-197.

47. Schoene, B., R. A. Fleischmann, H. Remmer, and H. F. von Oldershausen. 1972. Determination of drug metabolizing enzymes in needle biopsies of human liver. Eur. J. Clin. Pharmacol. 4: 65-73.

48. Doshi, J., A. Luisada-Opper, and C. M. Leevy. 1972. Microsomal pentobarbital hydroxylase activity in acute viral hepatitis. Proc. Soc. Exp. Biol. Med. 140: 492495.

49. Rowland, M. 1972. Drug administration and regimens. In Clinical Pharmacology: Basic Principles in Therapeutics. K. L. Melmon and H. F. Morelli, editors. The Macmillan Company, New York. 21-60.

50. Rowland, M., L. Z. Benet, and G. G. Graham. 1973. Clearance concepts in pharmacokinetics. J. Pharmacokinet. Biopharm. 1: 123-136. 